\title{
Efficacy of Percutaneous Ethanol Injection for Benign Neck Cyst
}

\author{
Jae Hoon Lee ${ }^{1}$, Si Won Yoon ${ }^{1}$, Heon Soo Park ${ }^{1}$, Myung Koo Kang ${ }^{1}$, \\ Joon Hyung Lee ${ }^{2}$, Ae Lan Jang ${ }^{3}$, and Jong Chul Hong \\ ${ }^{I}$ Departments of Otolaryngology-Head and Neck Surgery, ${ }^{2}$ Radiology, Dong-A University College of Medicine, Busan; and \\ ${ }^{3}$ Department of Medical Engineering, Dong-A University Graduate School, Busan, Korea
}

\section{경부 양성 낭종에서의 경피적 에탄올 주입술의 효과}

이재훈 ${ }^{1} \cdot$ 윤시원 $^{1} \cdot$ 박헌수 $^{1} \cdot$ 강명구 $^{1} \cdot$ 이준형 $^{2} \cdot$ 장애란 $^{3} \cdot$ 홍종철 $^{1}$

동아대학교 의과대학 이비인후-두경부외과학교실, ${ }^{1}$ 영상의학교실, ${ }^{2}$ 동아대학교 의학전문대학원 의공학과교실 ${ }^{3}$

\author{
Received January 18, 2016 \\ Revised March 22, 2016 \\ Accepted March 22, 2016 \\ Address for correspondence \\ Jong Chul Hong, MD, PhD \\ Department of Otolaryngology- \\ Head and Neck Surgery, \\ Dong-A University \\ College of Medicine, \\ 26 Daesingongwon-ro, Seo-gu, \\ Busan 49201, Korea \\ Tel +82-51-240-5428 \\ Fax +82-51-253-0712 \\ E-mailsanta@dau.ac.kr
}

Background and Objectives Advantages of percutaneous ethanol injection (PEI) were represented by insignificant mortality, minimal damage to normal parenchyma, relatively low cost and easy availability. The objective of the present study was to evaluate the efficacy of ethanol ablation as a minimally invasive management of cystic lesions in the neck or arising from the neck.

Subjects and Method Between August 2010 and December 2015, 28 patients with cystic lesions in the neck were diagnosed and treated with percutaneous ethanol injection. We evaluated the outcome of treatment using the alteration of volume reduction and the improvement of symptomatic and cosmetic complaints and complications.

Results The initial mean tumor volume was $21 \mathrm{~mL}$ (range, 1.6-36.9 mL), as shown by ultrasonography. The mean number of the treatment sessions was 3.5 (range, 1-9 sessions). At the last follow-up, the mean volume of the treated neck cyst decreased significantly from $21 \mathrm{~mL}$ to $2.7 \mathrm{~mL}(p<0.001)$. The average volume reduction rate was $82.4 \%$ with the success rate of procedure of $82 \%$. The mean symptoms and cosmetics visual analog scale improved from 5.4 to 2.4 and from 4.8 to $1.5(p<0.001)$. No significant complications were observed during follow-ups. Conclusion PEI is simple, easy, safe, and effective without surgical scars and hospitalization for neck cyst patients and favorable outcomes can be achieved without significant complications. It can be used as a substitute for surgery in the treatment of benign neck cyst lesions. Korean J Otorhinolaryngol-Head Neck Surg 2016;59(6):448-52

Key Words Ablation - Cyst $\cdot$ Ethanol $\cdot$ Neck.

\section{서 론}

림프관종(lymphangioma), 경부하마종(plunging ranula), 새 열낭종(branchial cleft cyst), 갑상설관낭종(thyroglossal duct cyst) 등과 같은 경부 낭종의 치료는 수술적 절제이지만, 술 중 신경손상, 재발 및 흉터 등의 문제를 야기할 수 있다. 이런 부작용을 줄이기 위해 경화요법을 비롯한 여러 가지 비수술적 인 치료가 시도되고 있다. 이에는 경피적 에탄올 주입술, $\mathrm{OK}^{-}$
432 주입술, 고주파절제술 및 레이저절제술 등이 있는데 이들 모두 낭성의 크기를 줄이고 증상을 개선한다고 보고되고 있 다.) 1989년 이후부터 알려진 경피적 에탄올 절제술(ethanol ablation)은 화학적 경화치료법(sclerotherapy)의 하나로서, 현 재까지 사용되어 오면서 낭성 갑상선 결절에 있어 64 99\%의 치료 효과가 있으며, 안전하고 쉬운 술기로 보고되고 있다. ${ }^{2,3)}$ 낭종 내 에탄올을 주입하게 되면 국소적인 혈관응고괴사와 섬유화 반응을 일으키고 소혈관 혈전과 조직 허혈을 초래함으 
로써 낭종의 재발을 억제하는 것으로 알려져 있다. ${ }^{4)}$ 그러나 이 시술은 대부분 갑상선 낭종 및 결절에 시행하였을 때 좋은 결 과를 얻는 것으로 보고되고 있으나, 이외 경부에 발생한 낭종 에 대한 에탄올 주입술은 보고 및 치료 성적에 관련된 연구는 거의 없다.

이에 저자들은 경피적 에탄올 주입술(percutaneous ethanol injection, $\mathrm{PEI})$ 을 시행한 경부 낭종 환자를 대상으로 치료 효과에 대해 알아보고자 하였다.

\section{대상 및 방법}

2010년 8월부터 2015년 12월까지 경부 낭종으로 본원 이비 인후과 외래를 방문한 환자에서 초음파 유도하 경피적 에탄올 주입술(ultrasound guided PEI) 시행한 환자 28명을 대상으 로 하였다. 28 명의 대상 환자 중 남자는 14 명, 여자는 14 명이었
으며, 연령분포는 평균 34.6세(15 78세)였다. 시술 전 신체검 사 및 초음파, 경부 컴퓨터단층촬영을 하였으며 낭종에 대해 세침흡입검사를 시행하여 악성 종물에 대한 감별진단을 시행 하여 악성 종물의 가능성을 배제하였다. 환자에게 수술적 방 법의 절제술와 경피적 에탄올 주입술의 장단점을 충분히 비 교 설명한 후 경피적 에탄올 주입술을 원하는 환자에게 시행 하였다. 한 명의 영상의학과 전문의에 의해 시행되었으며 도플 러 기능이 가능한 다주파수 5 12 MHz 변환기가 장착되어 있 는 디지털 초음파 스캐너(EsateTechnos, Genoa, Italy)를 사용 하였다. 시술 전, 후 낭종의 부피는 [낭종의 길이(length) $\times$ 너 비(width) $\times$ 높이(height) $\times \pi / 6$ ]으로 구했으며, 부피변화 비율 (Volume reduction rate, VRR)은 [(시술 전 부피 $(\mathrm{mL})$-시 술 후 부피 $(\mathrm{mL})) \times 100 /$ 시술 전 부피 $(\mathrm{mL})]$ 로 구하였다.

시술은 먼저 피부에 국소 표면마취를 시행한 후 초음파 유 도 하에 18 gauge 주사침을 이용하여 낭종 내의 액체를 가능

Table 1. Treatment outcomes of PEI

\begin{tabular}{|c|c|c|c|c|c|c|c|c|}
\hline Case & Gender & Age & Diagnosis & Follow-up (month) & Initial, vol (mL) & Last, vol (mL) & Treatment sessions & VRR \\
\hline 1 & $\mathrm{~F}$ & 46 & $B C C$ & 33 & 19.6 & 23.5 & 2 & -19.8 \\
\hline 2 & $M$ & 22 & $\mathrm{BCC}$ & 12 & 8.6 & 0 & 2 & 100 \\
\hline 3 & M & 30 & $\mathrm{BCC}$ & 36 & 6.7 & 0.5 & 6 & 92.5 \\
\hline 4 & M & 26 & $\mathrm{BCC}$ & 21 & 11.6 & 1.1 & 4 & 90.5 \\
\hline 5 & $\mathrm{~F}$ & 20 & $\mathrm{BCC}$ & 28 & 3.3 & 0.3 & 9 & 90.9 \\
\hline 6 & $\mathrm{~F}$ & 44 & $\mathrm{BCC}$ & 19 & 176 & 0 & 4 & 100 \\
\hline 7 & $\mathrm{~F}$ & 23 & $B C C$ & 13 & 73 & 11 & 4 & 84.9 \\
\hline 8 & $\mathrm{~F}$ & 49 & $B C C$ & 12 & 19 & 2.2 & 3 & 88.4 \\
\hline 9 & $M$ & 31 & Lymphangioma & 22 & 34 & 2.2 & 6 & 93.5 \\
\hline 10 & $\mathrm{~F}$ & 33 & Lymphangioma & 12 & 16 & 1.4 & 3 & 91.2 \\
\hline 11 & $\mathrm{~F}$ & 15 & Plunging ranula & 15 & 76 & 9.3 & 5 & 87.7 \\
\hline 12 & M & 29 & Plunging ranula & 18 & 9.5 & 0 & 2 & 100 \\
\hline 13 & $\mathrm{~F}$ & 15 & Plunging ranula & 15 & 12.4 & 4.3 & 4 & 65.3 \\
\hline 14 & M & 25 & Plunging ranula & 12 & 4.4 & 0 & 3 & 100 \\
\hline 15 & $\mathrm{~F}$ & 19 & TGDC & 12 & 6.9 & 0.3 & 3 & 95.6 \\
\hline 16 & M & 18 & TGDC & 18 & 36.9 & 2.2 & 6 & 94 \\
\hline 17 & M & 22 & TGDC & 13 & 1.9 & 1.5 & 3 & 21.1 \\
\hline 18 & M & 58 & TGDC & 13 & 4.6 & 0.01 & 3 & 99.7 \\
\hline 19 & M & 48 & TGDC & 21 & 2.9 & 0.2 & 4 & 93.1 \\
\hline 20 & $\mathrm{~F}$ & 17 & TGDC & 24 & 11.8 & 12.3 & 4 & -4.2 \\
\hline 21 & M & 76 & TGDC & 24 & 15 & 0.1 & 3 & 99.3 \\
\hline 22 & M & 23 & TGDC & 28 & 1.6 & 0 & 3 & 100 \\
\hline 23 & $\mathrm{~F}$ & 52 & TGDC & 25 & 7.2 & 0.4 & 3 & 94.4 \\
\hline 24 & M & 78 & TGDC & 11 & 3.4 & 0.2 & 2 & 94.1 \\
\hline 25 & $\mathrm{~F}$ & 47 & TGDC & 12 & 11.7 & 0.8 & 2 & 93.2 \\
\hline 26 & $F$ & 38 & TGDC & 12 & 5.2 & 0 & 2 & 100 \\
\hline 27 & $M$ & 34 & TGDC & 12 & 7.8 & 2.5 & 1 & 67.9 \\
\hline 28 & $\mathrm{~F}$ & 33 & TGDC & 12 & 2.8 & 0.1 & 2 & 96.4 \\
\hline Mean & & 34.6 & & 18 & 21 & 2.72 & 3.5 & 82.4 \\
\hline
\end{tabular}

M: male, F: female, BCC: branchial cleft cyst, TGDC: thyroglossal duct cyst, VRR: volume reduction rate, PEl: percutaneous ethanol injection 
한 많이 흡입하여 제거하였다. 이후 국소마취 및 낭종 내 찌꺼 기 제거의 목적으로 ${ }^{3,4)}$ 리도카인을 흡인한 액체 양의 $80 \%$ 가 량 주입하여 낭종을 세척한 후 다시 흡입하였다. $99 \%$ 에탄올 을 낭종의 부피 $80 \%$ 가량 주입하여 10 분 가량 기다린 후 다 시 흡입하였으며, 이후 낭종의 부피 $20 \%$ 가량의 에탄올을 낭 종 내 주입 후 시술을 마쳤다.

경과관찰 중 처음 낭종의 부피보다 $70 \%$ 가량 부피가 감소 하였을 때 시술이 성공한 것으로 판단하였으며, ${ }^{5)}$ 낭종의 부 피가 목적 치에 도달하지 못했을 시 1 2주 간격으로 경피적 에탄올 주입술을 반복하였다.

시술 전, 후 환자에게 낭종에 의한 증상 및 미용적 측면에 서의 시각상사척도(visual analog scale, VAS, 0 10)를 확인 하였다. 후향적으로 낭종의 부피 변화, 환자의 증상 및 미용 적 만족도, 재발 여부 등에 대해 자료를 분석하였다.

통계분석은 IBM SPSS 19.0(SPSS Inc., Chicago, IL, USA)을 사용하여 시술 전, 후 낭종의 부피 차이에 따라 비모 수 검정(Mann-Whitney U test)을 시행하였으며 최대 유의수
준은 0.05 로 설정하였다.

\section{결 과}

대상 환자 28 명 중 명 중 갑상설관낭종이 14 명, 새열낭종 8 명, 경부하마종이 4명, 림프관종 2명이었다. 평균 18(11 36개 월)개월 경과 관찰하였으며 평균 3.5회(1 9회)의 경피적 에 탄올 주입술을 시행하였다(Table 1). 내원 시 경부 낭종의 부 피는 시술 전 평균 $21 \mathrm{~mL}(1.6 \sim 36.9 \mathrm{~mL})$ 였으나 시술 후 평균 $2.7 \mathrm{~mL}(0 \sim 12.3 \mathrm{~mL})$ 로 통계학적으로 유의하게 감소하였으며 $(p<0.001)$, 전체 평균 $\mathrm{VRR}$ 은 $82.4 \%$ 이고 $\mathrm{VRR}$ 이 $70 \%$ 이상인 환자는 총 23명으로 $82 \%$ 의 성공률을 보였다(Table 1)(Figs. 1, 2, and 3). 각 질환별 평균 VRR은 갑성설관낭종 $81.7 \%$, 새열 낭종 $78.4 \%$, 경부하마종 $88.2 \%$, 림프관종 92.3\%였다(Fig. 4). 환자의 증상에 대한 $\mathrm{VAS}$ 는 시술 전 평균 5.4에서 시술 후 2.4점으로 $(p<0.001)$, 환자의 미용적 $\mathrm{VAS}$ 는 시술 전 평균 4.8 에서 시술 후 1.5 로 $(p<0.001)$ 통계학적으로 유의하게 감
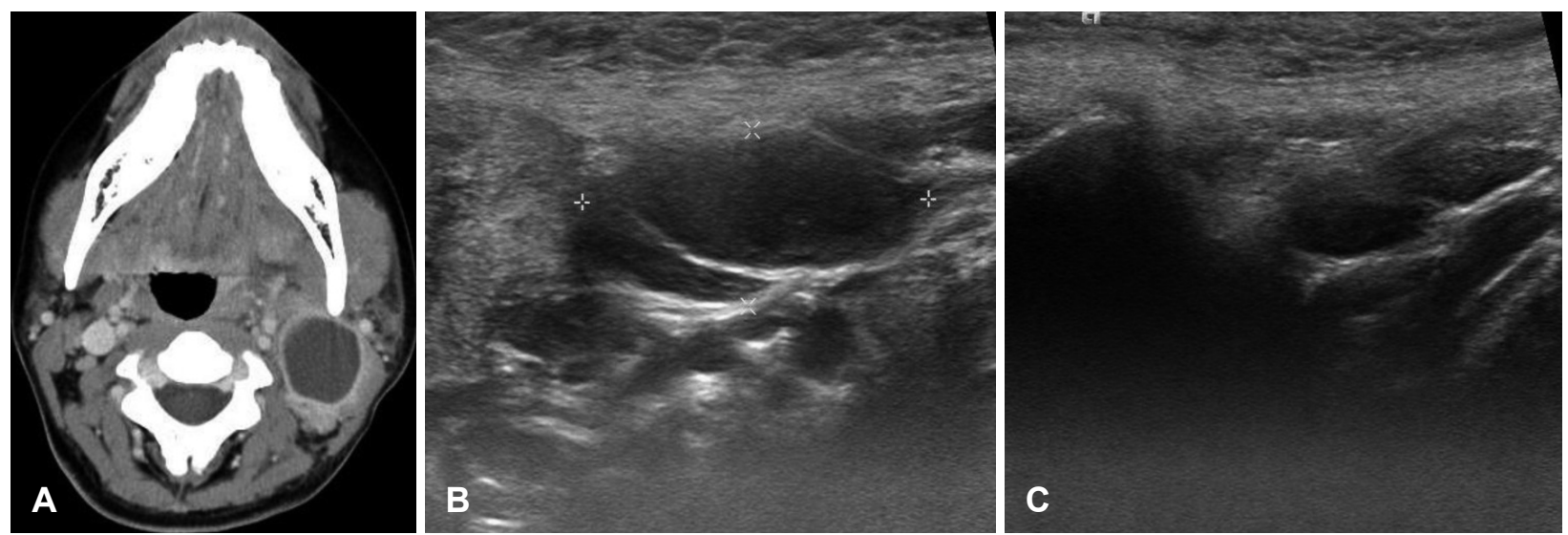

Fig. 1. Left second branchial cleft cyst, $3.3 \times 2.2 \times 2.3 \mathrm{~cm}$ sized, cystic mass lesion is found in the left retostyliod carotid space of left mandibular angle level (A). Initial ultrasonography shows a large cyst $(73 \mathrm{~mL})$ that underwent ethanol ablation (B). Cyst volume was reduced $(11 \mathrm{~mL})$ after 13 month of percutaneous ethanol injection. Volume reduction rate was $84.9 \%(C)$.
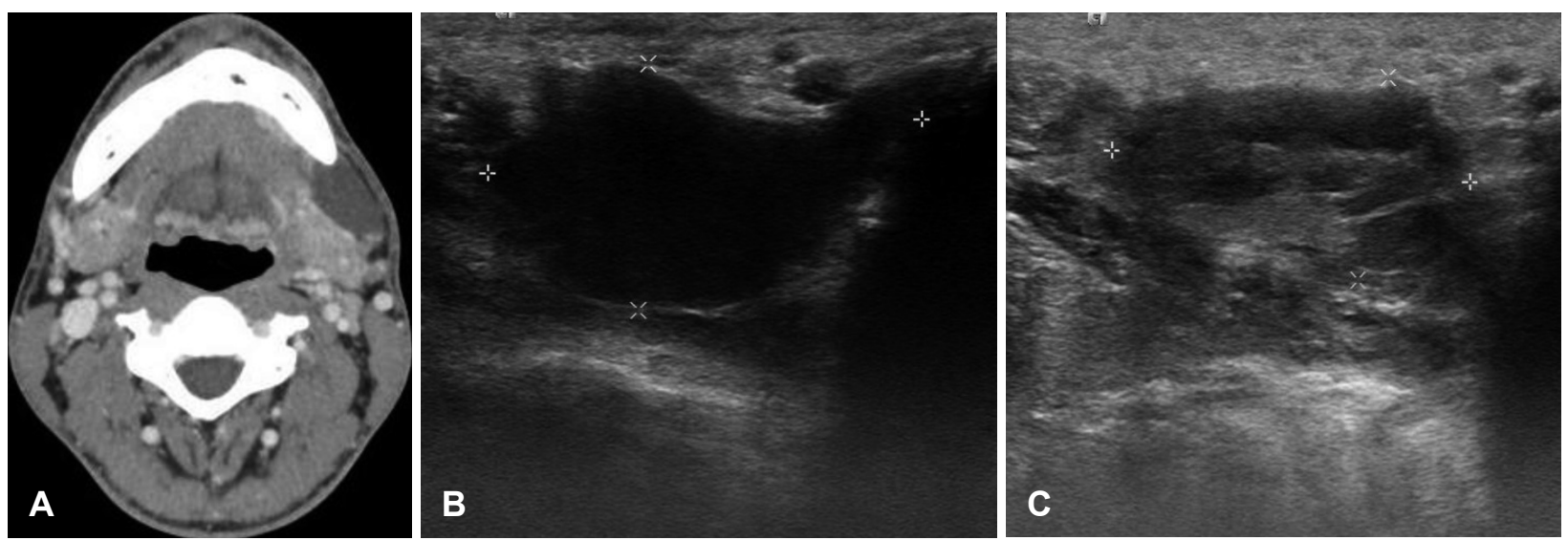

Fig. 2. Lymphangioma, $3.1 \times 1.7 \times 1.5 \mathrm{~cm}$ sized, cystic lesion is found in the left mandibular angle area. That is extended to the left sublingual space along left mandibular arch (A). Initial ultrasonography shows a large cyst $(34 \mathrm{~mL})$ that underwent ethanol ablation (B). Cyst volume was reduced $(2.2 \mathrm{~mL})$ after 22 month of percutaneous ethanol injection. Volume reduction rate was $93.5 \%$ (C). 

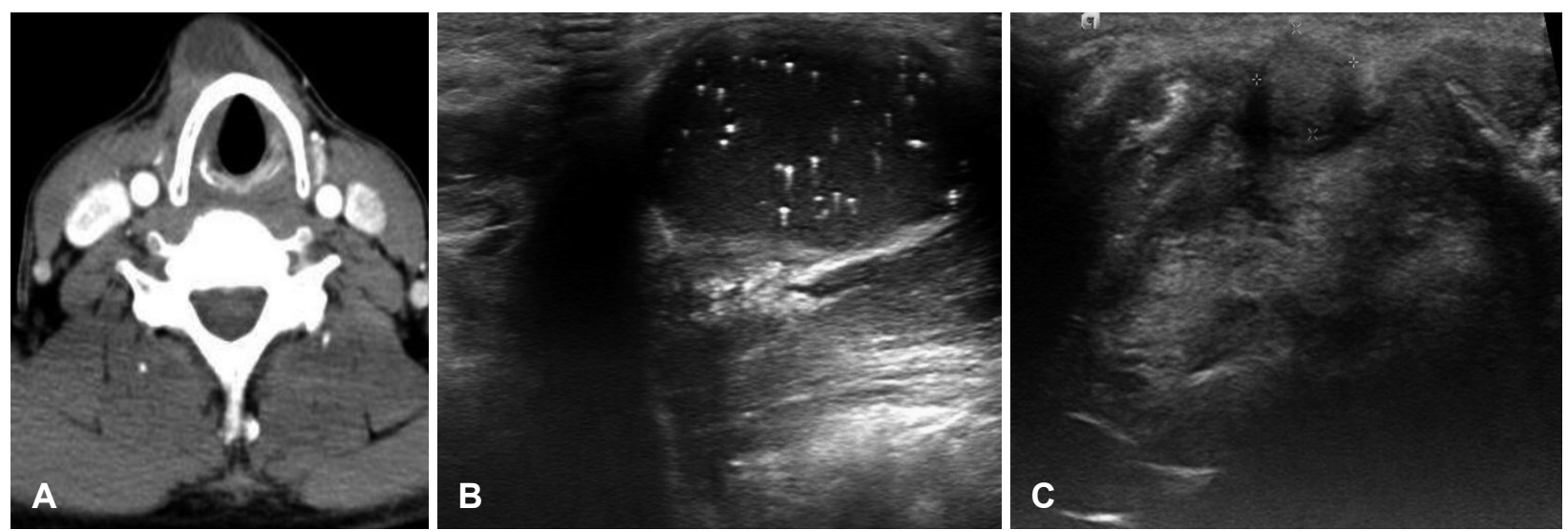

Fig. 3. Thyroglossal duct cyst, $2.2 \times 1.5 \times 1.7 \mathrm{~cm}$ sized, rim enhancing cystic mass which is embedded in strap muscle at right paramedian anterior neck just below hyoid (A). Initial ultrasonography shows a large cyst $(21 \mathrm{~mL})$ that underwent ethanol ablation (B). Cyst volume was reduced $(2.9 \mathrm{~mL})$ after 21 month of percutaneous ethanol injection. Volume reduction rate was $93.1 \%$ (C).

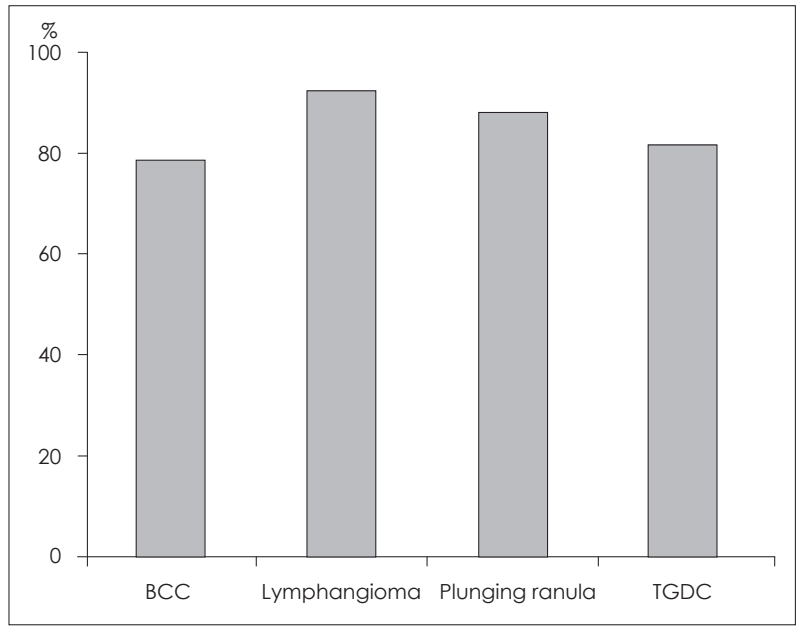

Fig. 4. Volume reduction rate of each disease after percutaneous ethanol injection (BCC: $78.4 \%$, lymphangioma: $92.3 \%$, plunging ranula: $88.2 \%$, TGDC: $81.7 \%$ ). BCC: branchial cleft cyst, TGDC: thyroglossal duct cyst.

소하였다(Fig. 5). 시술 후 특별한 부작용은 모든 시술에서 나타나지 않았다. 치료 후 치료 전보다 부피가 더 커진 갑상 설관낭종 1예, 새열낭종 1예에 수술을 권유하였으나 모두 거 부하였다.

\section{고 찰}

지금까지 경피적 에탄올 주입술에 대한 연구의 대부분은 갑 상선 실질 내 낭종 및 결절을 대상으로 한 것으로 좋은 결과들 을 보고하였지만) 대상을 경부 낭종으로 확대하여 체계적으 로 보고한 연구는 없다. 저자들은 경부에서 발생한 여러 낭종 에서 경피적 에탄올 주입술을 시행하여 그 결과를 관찰하였다.

경부 낭종에서 경피적 에탄올 주입술을 시행한 28예에서 경피적 에탄올 주입술을 시행한 후 최초 낭종의 부피의 $70 \%$ 이상 감소되었을 시 치료 성공으로 평가하였을 때 평균 18 개

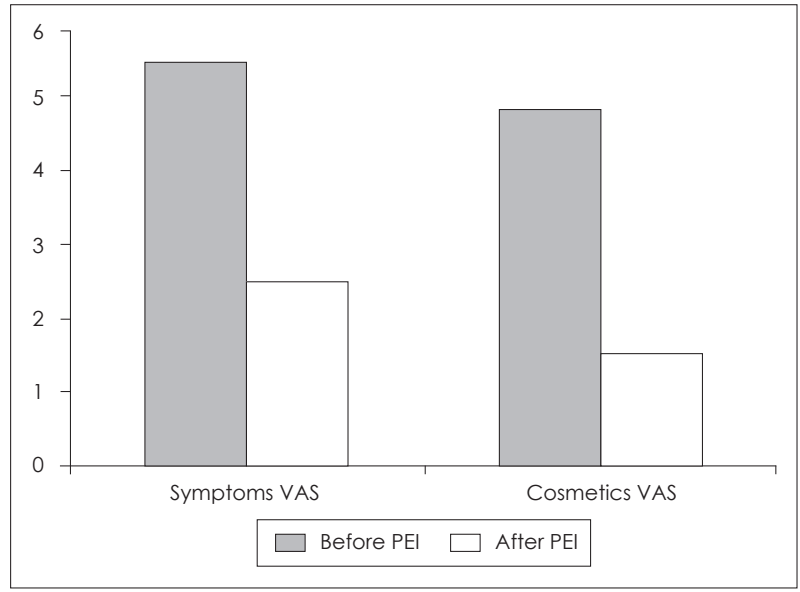

Fig. 5. Therapeutic effectiveness by symptoms and cosmetics visual analog scale (VAS) before and after percutaneous ethanol injection (PEI). Average patient's symptoms VAS before PEI were 5.4 point that decreased to 2.4 point after the procedure $(p<0.001)$. Also average patient's cosmetics VAS before PEI were 4.8 point that decreased to 1.5 point after the procedure $(p<0.001)$, significantly decreased statistically.

월 기간 동안 23예(82.1\%)에서 치료를 성공하였으며 환자가 호소하는 증상 및 미용적 효과에서 충분히 효과를 나타내었 다. 이는 갑상설관낭종에서의 경피적 에탄올 주입술 성공률 $(71 \%)^{4)}$ 경부 낭종의 OK-432 주입술 성공률(76\%) 등 과 비 교해 좋은 결과를 보였다.

경부에는 많은 종물이 발생할 수 있다. 15 세 이하의 소아 에서는 염증성 림프절염이 가장 빈번하고 다음으로 새열낭, 갑상설관낭, 혈관종, 유피낭, 악성 림프종의 순이다. 16 40세 에서는 염증성 림프절염, 선천성 이상, 악성림프종, 갑상선 악 성종양, 타액선종양, 악성종양의 경부 림프절전이의 순이며, 40세 이상군에서는 악성종양의 경부 림프절전이, 갑상선 악 성종양, 염증성 림프절염, 선천성 이상의 순이다.) 40 세 이하 에서 염증성 림프절염 이외 양성 질환의 많은 부분이 선천성 이상에 의한 낭성 종양이 차지하고 있으며 본원에서 경피적 
에탄올 주입술을 시행한 경부 낭종을 가지 환자의 평균 나이 역시 34.6세였다. 그래서 젊은 환자들에게 수술 없이 낭종을 제거할 수 있는 경피적 에탄올 주입술이 그 중요성이 크다고 생각할 수 있다.

현재까지 양성 경부 낭종은 대부분 수술적 절제를 첫 번째 치료로 시행하고 있다. 그러나 신경손상, 낭종의 재발, 미용적 문제 등의 수술 합병증이 발생할 수 있다. 게다가 해부학적으 로 경부 낭종을 주위 여러 부위와 유착이 되어 있을 가능성 이 높아 술기적 어려움도 있어 완전한 절제가 어려운 경우가 많다. 그래서 보다 안정하고 효과적인 많은 시술들이 연구되 어 왔다. 경부 낭종 및 종물의 앞에서 언급한 것과 같이 악성 종양이나 전이성 병변일 가능성이 있엉 영상의학적, 병리학 적 검사에 의해 양성 병변으로 밝혀지면 여러 다른 시술을 사용할 수 있다. ${ }^{9)}$ 현재까지 수술을 피하기 위해 경부 낭종 및 결절에서 단순흡입술, 경화요법, 고주파 절제술 및 레이저 절 제술 등이 시행되고 있으며 이들 모두 낭종 및 결절의 크기를 줄이고 증상을 개선하였다. ${ }^{10)}$ 이 중 경화요법은 sodium morrhuate를 이용하여 1933년 처음 시도되었으며 이후 iodine, ethanolamine oleate, alcohol, bleomycin, tetracycline, cyclophosphamide 등이 사용되었다. ${ }^{11)}$ 경부에서는 1976년 bleomycin을 이용한 cystic hygroma 경화요법을 사용하였고, ${ }^{12)}$ 1987년 lymphangioma에서 OK-432를 사용하였다. ${ }^{13)} 1989$ 년 Rozman 등 ${ }^{14)}$ 에 의해 처음 낭종성 갑상선 결절의 치료에 경 피적 에탄올 주입술이 시도된 이래, 양성 갑상선 질환의 치료 를 위한 다양한 연구가 있었으며 단순 흡인술과 비교하여 초 치료 및 재발성 결절에서의 높은 성공률을 보고하고 있 다. ${ }^{12,14)}$ 경피적 에탄올 주입술은 낭액을 제거한 후 에탄올을 주입하여 소혈관의 혈전과 응고괴사(coagulation necrosis)를 유발하여 중심부의 비가역적인 조직 손상과 주변부 세포내 부의 미세 조직과 효소 활성의 변이를 통한 가역적인 손상을 야기하여 낭성 결절의 재발을 억제하는 것으로 알려져 있 다. ${ }^{15,16)}$ 그러나 경피적 에탄올 주입술을 경부 낭종에 사용한 체계적인 보고가 없어 본 연구를 시행하였으며, 경부 낭종에 서 역시 경피적 에탄올 주입술이 좋은 치료 효과를 가진다는 것을 증명하였다. 확실한 효과를 가지기 위해 경피적 에탄올 주입술 시행 중 낭종의 전체 벽에 에탄올이 묻어야 하며 그 를 위해 낭종의 부피의 $50 \%$ 를 $95 \%$ 에탄올로 대체시켜야 한 다. 이때 체내로 흡수된 에탄올에 의한 알코올 독성을 방지하 기 위해 최대 에탄올 용량 제한이 필요하다. ${ }^{17)}$

목은 다른 신체부위보다 단면적이 작기 때문에 조금의 부 피 변화에도 환자가 느끼는 불편감이나 미용적 변화를 크게 느낄 수 있다. 그래서 경피적 에탄올 주입술 시행 후 낭종의 부피 변화에 의한 만족도는 VAS에서 유의한 변화 $(p<0.001)$
를 보여주었다.

경피적 에탄올 주입술과 같은 낭종의 경화요법에서 가장 흔한 합병증은 시술부위의 경한 통증이나 ${ }^{3)}$ 시술 전 국소 표 면 마취 및 낭종 내 세척 시 리도카인을 사용한다면 충분히 예방 가능하며, 본 연구에서 관찰되지 않았다.

\section{Acknowledgments}

This study was supported by research funds from Dong-A University.

\section{REFERENCES}

1) Sung JY, Baek JH, Kim KS, Lee D, Yoo H, Kim JK, et al. Singlesession treatment of benign cystic thyroid nodules with ethanol versus radiofrequency ablation: a prospective randomized study. Radiology 2013;269(1):293-300.

2) Valcavi R, Frasoldati A. Ultrasound-guided percutaneous ethanol injection therapy in thyroid cystic nodules. Endocr Pract 2004;10(3): 269-75.

3) Lee SJ, Ahn IM. Effectiveness of percutaneous ethanol injection therapy in benign nodular and cystic thyroid diseases: long-term follow-up experience. Endocr J 2005;52(4):455-62.

4) Lee DK, Seo JW, Park HS, Kang MK, Jang AL, Lee JH, et al. Efficacy of ethanol ablation for thyroglossal duct cyst. Ann Otol Rhinol Laryngol 2015;124(1):62-7.

5) Kim MG, Kim SG, Lee JH, Eun YG, Yeo SG. The therapeutic effect of OK-432 (picibanil) sclerotherapy for benign neck cysts. Laryngoscope 2008;118(12):2177-81.

6) Ohta N, Fukase S, Watanabe T, Ito T, Aoyagi M. Effects and mechanism of OK-432 therapy in various neck cystic lesions. Acta Otolaryngol 2010;130(11):1287-92.

7) McGuirt WF. Differential diagnosis of neck masses. In: Cummings CW, Fredrickson JM, Harker LA, Krause CJ, Schuller DE, editors. Otolaryngology-Head and Neck Surgery. 4th ed. St. Louis: Mosby Year Book; 2005. p.2540-53.

8) Sung MW, Lee DW, Kim DY, Lee SJ, Hwang CH, Park SW, et al. Sclerotherapy with picibanil (OK-432) for congenital lymphatic malformation in the head and neck. Laryngoscope 2001;111(8):1430-3.

9) Fukumoto K, Kojima T, Tomonari H, Kontani K, Murai S, Tsujimoto F. Ethanol injection sclerotherapy for Baker's cyst, thyroglossal duct cyst, and branchial cleft cyst. Ann Plast Surg 1994;33(6):615-9.

10) Sung JY, Baek JH, Kim KS, Lee D, Yoo H, Kim JK, et al. Singlesession treatment of benign cystic thyroid nodules with ethanol versus radiofrequency ablation: a prospective randomized study. Radiology 2013;269(1):293-300.

11) McClatchey KD, Appelblatt NH, Zarbo RJ, Merrel DM. Plunging ranula. Oral Surg Oral Med Oral Pathol 1984;57(4):408-12.

12) Yura J, Hashimoto S, Mizuno T. Cervical tumors and cysts of children with special reference to bleomycin therapy for cystic hygroma. Japenese J Surg Int Med 1976;8:279-85.

13) Ikarashi T, Inamura K, Kimura Y. Cystic lymphangioma and plunging ranula treated by OK-432 therapy: a report of two cases. Acta Otolaryngol Suppl 1994;511:196-9.

14) Rozman B, Bence-Zigman Z, Tomic-Brzac H, Skreb F, Pavlinovic Z, Simonovic I. Sclerosation of thyroid cysts by ethanol. Periodicum Biologorum 1989;91:1116-8.

15) Bennedbaek FN, Hegedüs L. Treatment of recurrent thyroid cysts with ethanol: a randomized double-blind controlled trial. J Clin Endocrinol Metab 2003;88(12):5773-7.

16) Crile G Jr. Treatment of thyroid cysts by aspiration. Surgery $1966 ; 59$ (2):210-2.

17) Cheng D, Amin P, Ha TV. Percutaneous sclerotherapy of cystic lesions. Semin Intervent Radiol 2012;29(4):295-300. 